\title{
Sobre as lacunas e respectivos mecanismos supletivos
}

\author{
About gaps and their respective supplementary \\ mechanisms
}

REIS FRIEDE Centro Universitário Augusto Motta - UNISUAM

Resumo O ordenamento jurídico constituiu um sistema de normas jurídicas, do que se infere que as normas em questão não se encontram dispostas isoladamente, mas se relacionam umas com as outras, formando um sistema provido dos atributos da unidade, coerência e completude. A ausência de uma norma é tradicionalmente denominada de lacuna, problema que, nos termos da atual Lei de Introdução às Normas do Direito Brasileiro, há de ser solucionado por meio dos mecanismos supletivos nela elencados (analogia, costume e princípios gerais do Direito), problemática que justifica uma investigação acadêmica a respeito do assunto. Com efeito, o presente estudo objetiva analisar a questão das lacunas e suas diversas espécies, discorrendo, ainda, sobre o debate acerca da existência (ou não) de tal fenômeno no Direito, culminando por abordar os respectivos mecanismos de integração. Para tanto, metodologicamente, o autor realiza uma revisão do pensamento de autores que se dedicaram ao tema. Como resultado a ser alcançado, espera-se contribuir para a orientação dos operadores do Direito quanto ao processo de suprimento das lacunas.

Palavras-chave: Lacuna. Analogia. Costume. PrincíPios gerais do DiREITO. 
Abstract The legal system constituted a system of legal norms, from which it is inferred that the norms in question are not arranged in isolation, but relate to each other, forming a system provided by the attributes of unity, coherence and totality. The absence of a norm is traditionally called a gap, a problem that, under the current Law of Introduction to the Norms of Brazilian Law, must be solved through the complementary mechanisms listed therein (analogy, custom and general principles of Law), question that justifies an academic investigation on the subject. In fact, the present study aims to analyze the question of gaps and their several varieties, discussing the debate about the existence (or not) of such phenomenon in Law, culminating in approaching the respective mechanisms of integration. For this, methodologically, the author carries out a review of the thinking of authors who have dedicated themselves to the theme. As a result to be achieved, it is hoped to contribute to the guidance of legal operators regarding the process of supplying the gaps.

Key-words: Gap. Analogy. Custom. General principles of LaW.

\section{INTRODUÇÃO}

O ordenamento jurídico, caracterizado por sua complexidade intrínseca, pode ser traduzido, em linhas gerais, como um conjunto de normas jurídicas. Não obstante a simplicidade de tal definição, trata-se de expressão que abrange muito mais elementos, independentemente das diversas naturezas e classificações que se lhe possam atribuir (FERRAZ JR., 2015, p. 139-140).

No preâmbulo do capítulo I da obra intitulada Teoria do Ordenamento Jurídico, BOBBIO (1999, p. 19) menciona uma frase cuja essência sintetiza boa parte do conteúdo teórico a ser desenvolvido neste texto: "as normas jurídicas nunca existem isoladas, mas sempre em um contexto de normas com relações particulares entre si". A presente citação evidencia, em primeiro lugar, que "as regras jurídicas constituem sempre uma totalidade", isto é, formam um ordenamento jurídico, não obstante a existência de normas das mais variadas naturezas temáticas 
(constitucionais, processuais, penais, civis, administrativas, eleitorais, tributárias, ambientais etc). Da mesma forma, a referida elocução põe em relevo a importância não apenas do estudo da norma jurídica individualmente considerada (assunto a ser abordado no âmbito da Teoria da Norma), mas, também, de sua inter-relação com outras normas integrantes de um dado sistema, vocábulo que, segundo argumenta SOARES (2013, p. 111), pode ser semanticamente definido como "toda ordenação racional de elementos naturais ou sociais, a qual pode ser decomposta analiticamente em duas dimensões", quais sejam, o repertório (elementos que integram o sistema) e a estrutura (padrão de organização dos referidos elementos sistêmicos).

Bobbio, reconhecendo que a norma jurídica era tradicionalmente a única perspectiva por meio da qual se estudava o Direito, posto que não se concebia o ordenamento jurídico como um objeto autônomo de estudo, propõe, na aludida obra, uma teoria destinada a analisá-lo, separada e particularmente. Assim, diante da verificação de que as normas jurídicas não existem, mas, sim, coexistem, é possível afirmar que a Teoria do Ordenamento Jurídico constitui-se em uma das mais relevantes contribuições de Bobbio para a compreensão do fenômeno jurídico no seu aspecto global. Afinal, conforme afirma o autor italiano, o ordenamento jurídico, "além de regular o comportamento das pessoas, regula também o modo pelo qual se devem produzir as regras". Igualmente considerando o caráter sistêmico inerente ao ordenamento jurídico, Kelsen (1987, p. 207), na célebre Teoria Pura do Direito, assevera que "todas as normas cuja validade pode ser reconduzida a uma e mesma norma fundamental formam um sistema de normas, uma ordem normativa". Nota-se, portanto, que Kelsen e Bobbio procuram demonstrar que o fenômeno jurídico não é representado apenas pela norma particularmente concebida, mas também por um autêntico sistema normativo.

A doutrina nacional também alude a tal caráter sistêmico do ordenamento jurídico, atributo assinalado, por exemplo, por Silva (2015, p. 35), mormente quando afirma que o Direito é um "fenômeno histórico-cultural, realidade ordenada, ou ordenação normativa da conduta segundo uma conexão de sentido", consistindo, portanto, em um "sistema 
normativo", fenômeno que se operou ao longo do tempo, conforme explica Lafer (1988, p. 39).

\section{O PROBLEMA DAS LACUNAS}

Com o surgimento do Estado moderno, fundado no primado da lei, pretendeu-se, entre outros aspectos, construir um sistema jurídico cujas regras positivas fossem suficientemente abrangentes, de modo a abarcar todas as situações jurídicas passíveis de serem estabelecidas no âmbito das relações intersubjetivas. Tal aspiração revela uma verdadeira utopia do ser humano, dada a inconteste impossibilidade de o Direito estatal (por mais desenvolvido que possa ser) prever (e regular) o amplo universo das relações sociais dotadas de relevância jurídica, sobretudo se considerarmos que o legislador, enquanto ser falível e limitado no que se refere ao poder de previsão, não consegue acompanhar pari passu a dinâmica transformadora da realidade social. Assim, não raro aparecem casos desprovidos de previsão normativa, originando as denominadas lacunas, tema em torno do qual paira interessante discussão, conforme registrado por Ferraz Jr.

Historicamente, o problema das lacunas surge como questão teórica desde o momento em que a ideia de sistema impõe-se à concepção do ordenamento. Ela é, portanto, fruto da Era Moderna, da centralização e do monopólio da violência nas mãos do Estado e, consequentemente, do domínio sistemático da produção de normas, bem como da onipresença do legislador em relação a todos os comportamentos socialmente possíveis (FERRAZ JR., 2015, p. 178).

O termo lacuna, para Diniz (2002, p. 70), pode ser conceituado como sendo "faltas ou falhas de conteúdos de regulamentação jurídico-positiva para determinadas situações fáticas, que admitem sua remoção por uma decisão judicial jurídico-integradora". Ainda, segundo a mesma autora (DINIZ, 2001, p. 10), constitui-se a lacuna em um estado 
incompleto do sistema, defeito que necessita ser colmatado, do que resulta a importante missão a ser desempenhada pelo artigo $4^{\circ}$. da Lei de Introdução às Normas do Direito Brasileiro (Decreto-Lei nº 4.657/42), regra que concebe ao "magistrado, impedido de furtar-se a uma decisão, a possibilidade de integrar ou preencher a lacuna, de forma que possa chegar a uma solução adequada". Tal providência, que a doutrina convencionou chamar de integração normativa, caracteriza, em última análise, o "desenvolvimento aberto do Direito, dirigido metodicamente, em que o aplicador adquire consciência da modificação que as normas experimentam, continuamente, ao serem aplicadas às mais diversas relações da vida, chegando a apresentar, na ordem normativa, omissões concernentes a uma nova exigência da vida".

Com efeito, identificada uma lacuna, cumpre ao intérprete solucioná-la, devendo, para tanto, proceder nos termos do artigo $4^{\circ}$. da Lei de Introdução às Normas do Direito Brasileiro, assim explicados por Gusmão:

Mas, como proceder o juiz no caso de lacuna? Primeiro, servindo-se do processo de auto-integração ou de expansão do ordenamento jurídico, isto é, da analogia. Processo aplicável a qualquer campo do Direito, menos no Direito Penal nos países que acolhem o princípio de legalidade: não há crime ou pena sem lei penal que expressamente o preveja de antemão. Feita essa ressalva, pode-se dizer que muitos casos não previstos pelo legislador podem ser resolvidos com recurso à analogia, desde que o intérprete encontre no sistema jurídico, ou seja, no Ordenamento Jurídico, hipótese semelhante à sub judice. É, pois, a analogia processo de aplicação de um princípio jurídico estatuido para determinado caso a outro que, apesar de não ser igual, é semelhante ao previsto pelo legislador, ou, mas singelamente, extensão do tratamento jurídico, previsto expressamente na lei para determinado caso, a um semelhante, não previsto. [...]. Mas nem sempre pode ser encontrada norma reguladora de caso semelhante. Não havendo, segundo nosso Direito e nossa doutrina, o juiz deverá decidir o caso pelos princípios gerais do Direito (GUSMÃO, 2000, p. 237). 
Oportuno mencionar que em relação ao emprego da analogia em Direito Penal, segundo pacífica doutrina penalista, a vedação já referida por Gusmão somente alcança a analogia in malam partem (prejudicial ao réu), nada impedindo que se utilize a analogia in bonam partem (favorável ao réu).

\section{O DEBATE SOBRE A EXISTÊNCIA DE LACUNAS NO DIREITO}

Situando a importância do assunto ora abordado, Streck (2007, p. 104-105) comenta que "a discussão sobre a existência (ou não) de lacunas no Direito" adquire relevância, fundamentalmente, sob dois pontos de vista. De início, segundo assevera Streck, o debate em torno da questão "é importante para a própria Dogmática Jurídica, na medida em que a tese das lacunas serve como forte entendimento norteador e, também, como sustentáculo ao Direito visto de maneira circular e controlado"; ademais, prossegue o ilustre professor, atua como "argumento desmistificador do próprio dogma do Direito baseado no modelo napoleônico, pois pode-se entender, sem dúvida, que, quando o juiz está autorizado/obrigado a julgar" nos termos dos artigos $4^{\circ}$. da LICC [atual Lei de Introdução às Normas do Direito Brasileiro] e 126 do [antigo e ora revogado] CPC (isto é, deve sempre proferir uma decisão), "isso significa que o ordenamento é, dinamicamente, completível, através de uma autorreferência ao próprio sistema jurídico".

O texto da lavra de Streck demonstra que o tema ora desenvolvido é objeto de controvérsia na doutrina. Assim, no âmbito da mesma questão, Diniz (2001, p. 94) assevera que alguns autores rejeitam a existência de lacunas no sistema em si, sob o principal argumento de que o ordenamento forma um todo orgânico suficientemente capaz de disciplinar todos os comportamentos humanos. Em contraposição, outra concepção doutrinária sustenta que o sistema, por mais perfeito que possa ser, não consegue prever todas as situações fáticas que constantemente ocorrem na realidade social, admitindo, pois, o 
fenômeno das lacunas no âmbito do próprio sistema jurídico. Diniz, de sua parte, não concorda com a perspectiva teórica que concebe o sistema normativo como algo fechado, hermético, entendimento que, em linhas gerais, funda-se no princípio segundo o qual "tudo que não está proibido, está permitido". Depreende-se, portanto, que a referida autora, ao rejeitar o dogma que pugna plenitude do ordenamento jurídico, acaba por admitir a ocorrência de lacuna no próprio Direito.Não as aceitamos porque, no nosso entender, esse princípio não constitui uma norma jurídica positiva, não conferindo, portanto, direitos e obrigações a ninguém, sendo, assim, um mero enunciado lógico, inferido da análise do sistema normativo.

Considerado sob o prisma da linguagem, seria uma metalinguagem, porquanto se dirige a linguagem-objeto, sendo, nesse sentido, uma proposição descritiva, formal ou lógica, isto é, analítica, posto que não se refere ao mundo fático. $\mathrm{O}$ que vem a comprovar, uma vez mais, a falta de normatividade do referido dogma. Com isso, essas teorias fracassam no empenho de sustentar que todo o sistema jurídico é uno, completo, independente e sem lacunas, pois concebe o Direito sob uma perspectiva estática.

Todavia, é importante assinalar [...], a diferença entre o postulado da plenitude, de acordo com o qual todos os sistemas jurídicos são completos, e a exigência de que o sejam. O postulado é uma mera ilusão que, não obstante, desempenha um papel ideológico definido no pensamento jurídico; a sua exigência responde a um ideal puramente racional, independente de toda atitude política. A exigência da completude é caso especial de um princípio mais geral, inerente a toda investigação científica enquanto atividade racional. [...].

É de se ver, portanto, que a teoria das lacunas não deve ser analisada sob uma orientação estática do Direito, porque isso traz como consequência uma visão errônea do fenômeno. O Direito deve ser considerado sobre o prisma dinâmico, em constante mutação, sendo, assim, lacunoso, no nosso entendimento (DINIZ, 2001, p. 96 e 99). 
Kelsen, lembrado por Diniz (2001, p. 100), igualmente rejeita a ideia "de lacunas no sistema, pois todo e qualquer comportamento pode ser considerado como regulado - num sentido positivo ou negativo pela ordem jurídica", disso resultando "o caráter da completude ou da plenitude do sistema normativo". Na concepção de Kelsen, consoante afirma Diniz, "as normas que o compõem contêm, em si, a possibilidade de solucionar todos os conflitos levados à apreciação dos magistrados ou órgãos competentes".

Ainda no que se refere ao mesmo debate, Diniz (2001, p. 99-100) anota que uma parte da doutrina, ao examinar o problema em epígrafe, considera as lacunas jurídicas como uma questão pertinente ao âmbito processual, uma vez que, segundo tal entendimento, tais figuras "somente surgem por ocasião da aplicação de normas a determinado caso para o qual não há, real ou aparentemente, norma específica”.

Ademais, fundamentando-se no princípio da proibição do non liquet, há quem recuse até mesmo a própria existência de lacunas, sob o principal argumento de que existem pessoas (vale dizer, os juízes) encarregadas e obrigadas a prover uma solução para toda e qualquer questão jurídica, por mais inédita que possa ser.

Não obstante os entendimentos já citados, não há como negar a efetiva existência de lacunas no Direito, posto que, conforme bem explica Diniz (2000, p. 443), “se não se admitisse o caráter lacunoso do Direito, sob o prisma dinâmico, o Poder Legislativo, em um dado momento, não mais teria qualquer função", tendo em vista que "todas as condutas já estariam prescritas", mormente diante do princípio pelo qual o que não está proibido, está prescrito.

Da mesma forma, a tese segundo a qual não há lacunas porque há juízes não merece acolhimento, notadamente se considerarmos que a função do magistrado, nesse particular, é justamente identificá-las e colmatá-las, criando apenas uma norma de caráter individual, permanecendo intacta a lacuna constatada na lei, uma vez que "o caso sub judice por ele resolvido não pode generalizar a solução para outros casos, mesmo que sejam idênticos". 


\section{EsPÉCIES DE LACUNAS}

Consoante leciona Bobbio (1999), a doutrina, de um modo geral, alude às seguintes espécies de lacunas:

a) Lacuna própria (real ou de iure condito; inerente ao Direito já estabelecido), isto é, lacuna do sistema ou dentro do sistema, e lacuna imprópria (ideológica ou de iure condendo; pertinente ao Direito a ser estabelecido), ou seja, que deriva da comparação do sistema real com o sistema ideal, ambas distinguidas da seguinte forma:

A gravidade do conflito deriva do fato de que estão em jogo dois valores fundamentais de todo Ordenamento Jurídico, o do respeito da ordem, que exige o respeito da hierarquia e, portanto, do critério da superioridade, e o da justiça, que exige a adaptação gradual do Direito às necessidades sociais $\mathrm{e}$, portanto, respeito do critério da especialidade (BOBBIO, 1999, p. 107).

Outra diferença possível de ser apontada, segundo as lições do professor Bobbio, reside no modo pelo qual podem ser decididas cada uma das aludidas espécies. Assim, a lacuna imprópria somente é solucionada "através da formulação de novas normas", sendo resolvível pelo legislador; a lacuna própria, por sua vez, resolve-se mediante "as leis vigentes", preenchidas por obra do intérprete.

De qualquer modo, delimitando o âmbito do estudo sob comento, Bobbio (1999, p. 144) adverte que "quando se diz que o sistema está incompleto, diz-se em relação às lacunas próprias, e não às impróprias", ou seja, o "problema da completude do Ordenamento Jurídico é se há e como podem ser eliminadas as lacunas próprias".

b) Lacuna objetiva ("aquela que depende do desenvolvimento das relações sociais, das novas invenções, de todas aquelas causas que provocam o envelhecimento dos textos legislativos e que, portanto, independe da vontade do legislador") e lacuna subjetiva ("que depende de algum motivo imputável ao legislador") (BOBBIO, 1999, p. 144). A lacuna subjetiva, por sua vez, divide-se em lacuna voluntária ("aquela 
que o próprio legislador deixa de propósito, quando a matéria é muito complexa e não pode ser regulada com regras muito miúdas", razão pela qual "é melhor confiá-la, caso por caso, à interpretação do juiz") e lacuna involuntária (que decorre de um "descuido do legislador, que faz parecer regulamentado um caso que não o é, ou faz deixar de lado um caso que talvez se considere pouco frequente, etc".) (BOBBIO, 1999, p. 144).

c) Lacuna praeter legem ("quando as regras, expressas para serem muito particulares, não compreendem todos os casos que podem apresentar-se a nível dessa particularidade") e lacuna intra legem ("que tem lugar, ao contrário, quando as normas são muitos gerais e revelam, no interior das disposições dadas, vazios ou buracos que caberá ao intérprete preencher”) (BOBBIO, p. 144).

Em adição, Diniz, recorrendo-se de substanciosa doutrina estrangeira sobre o tema, refere-se às seguintes espécies de lacunas:

d) Lacuna autêntica ("quando, a partir de uma análise da lei, é impossível a obtenção de uma decisão a um caso concreto", figura que, segundo a mencionada autora, corresponde efetivamente a uma lacuna jurídica) e lacuna inautêntica ("quando o fato-tipo está previsto em disposição legal, mas a solução possível é tida como insatisfatória ou falsa", configurando, assim, somente uma lacuna politica), classificação apresentada por Zitelmann (DINIZ, 2007, p. 84).

e) Lacuna de lege ferenda (também chamada de lacuna político-jurídica, crítica ou imprópria, é aquela que existe do "ponto de vista de um Direito mais perfeito", razão pela qual apenas pode motivar o Legislativo a reformulá-lo, mas não o Judiciário a uma colmatação da referida lacuna) e lacuna de lege lata (lacuna no Direito vigente, passível de ser, portanto, colmatada), esquema classificatório retratado por Engisch (DINIZ, 2002, p. 84).

f) Assevera Diniz (2002, p. 86-87) que a classificação estabelecida entre lacunas autênticas e lacunas inautênticas pode ser desdobrada nas seguintes vertentes: lacuna voluntária ou intencional ("a que o legislador, propositadamente, deixa em aberto, porque a matéria, por ser assaz complexa, exigiria normas excessivamente minuciosas") e 
lacuna involuntária ou não-intencional ["a que pode surgir quando o elaborador da norma não observou o Direito cabalmente", seja porque a matéria não existia na época (lacuna desculpável), seja porque não examinou o caso corretamente (lacuna indesculpável)].

g) Lacuna normológica ("pertinente à ausência de normas requeridas por outras") e lacuna dikelógica ("que ocorre na falta de normas requeridas pela justiça"). Esta, por seu turno, pode ser classificada em lacuna direta ("se tal omissão se deve a motivos históricos em que o legislador não pôde prever a necessidade das normas") e lacuna indireta ("se as normas existentes são tão injustas que não podem ser aplicadas"), modelo classificatório atribuído a Werner Goldschmidt (DINIZ, 2002, p. 87).

h) Lacuna transcendente ("ausência total de regulamentação de um fato social") e lacuna imanente ("que existe dentro da Ordem Jurídica, enquanto esta disciplina uma determinada questão e não outra que se encontra intimamente correlacionada com ela"). (sic)

i) Lacuna primária ou originária ("existente na Ordem Normativa desde o momento de sua gênese") e lacuna secundária, derivada ou posterior ("a que aparece posteriormente, seja em consequência de uma modificação da situação fática ou de aparecimento de figuras contratuais que não se encaixem nos tipos jurídicos predeterminados de um sistema, ou devido a uma mutação de valores em relação à Ordem Jurídica"), distinção assinalada pela doutrina alemã (DINIZ, 2002, p. 88).

j) Lacuna deontológica [que corresponde a uma "inadequação da Ordem Normativa ao dever-ser (Sollen)"] e lacuna ontológica [que corresponde a uma "inadequação da Ordem Normativa ao ser (Sein)"]. Da lacuna deontológica resulta a lacuna ideológica ("relacionada a um critério transcendente, isto é, extrínseco à Ordem Jurídica, expressando a ausência de uma qualificação justa de um comportamento e a presença de uma norma que difere daquilo que se estima como justo") e a lacuna teleológica ou técnica ("que apresenta uma inadequação da Ordem Normativa a um fim imanente à própria ordem, contendo uma ausência de eficácia"). De igual modo, a lacuna ontológica pode se apresentar sob a forma de lacuna crítica ("quando for impossível uma avaliação 
deôntica de um comportamento de acordo com a norma, devido à incompletude da Ordem Jurídica") ou lacuna diacrítica ("que deriva da impossibilidade de uma decisão ou de uma resolução para o caso concreto controvertido"). No que se refere a tal vertente classificatória, cuja elaboração é conferida a Amedeo Conte, esclarece Diniz (2002, p. 89-90) que "as lacunas ontológicas e as deontológicas ideológicas são lacunas do Direito, ao passo que as lacunas deontológicas teleológicas são lacunas no Direito".

k) DINIZ (2002, p. 86-87) refere-se, ainda, a uma classificação apresentada por Ulrich Klug:

Bastante interessante é a classificação proposta por Ulrich Klug, tendo por base a consideração do problema das lacunas como uma inadequação entre um sistema de normas $\mathbf{N}$, e um conjunto de fatos $\mathbf{S}$, classificando as lacunas do seguinte modo: lacunas verdadeiras e lacunas não-verdadeiras. Ter-se-iam as primeiras quando a solução para o estado de coisas $\mathbf{S}$ falta no sistema normativo $\mathbf{N}$, e as segundas quando $\mathbf{S}$ é disciplinado por $\mathbf{N}$, porém a solução é tida como falsa, porque não satisfaz; lacunas intencionais e não-intencionais, que, no mesmo sentido abordado anteriormente, dependem da vontade do legislador; lacunas primárias e secundárias, sendo as primeiras já existentes por ocasião do nascimento do sistema normativo $\mathbf{N}$, e as segundas as que se manifestariam mais tarde; lacunas da lei e do Direito, que se distinguem se se admitir a existência de dois sistemas normativos N1 e N2, onde N1 seria a ordem legal positiva, e N2, uma ordem de direito supralegal, e as lacunas surgiriam, no primeiro caso, como a falta de norma no sistema N1, e no segundo, como a ausência de norma do sistema N2 supralegal; lacunas provisórias da lei, que apareceriam, admitindo-se a referida existência dos sistemas $\mathbf{N 1}$ e $\mathbf{N} 2$, onde a falta de norma no N1 é preenchida por norma de $\mathbf{N 2}$; lacunas imanentes e transcendentes, que requerem a consideração de dois sistemas de normas, sendo imanente a oriunda de uma falha no sistema $\mathbf{N} 1$ e transcendente a advinda do $\mathbf{N} 2$, considerando-se que o conjunto de fatos $\mathbf{S}$ esteja apenas disciplinado por N1 (DINIZ, 2002, p. 92-93).l) Ulrich Klug, citado por Diniz (2002, p. 93), aduz, ainda, às lacunas de conflito, as quais corresponderiam a 
uma "contradição de duas normas de um sistema normativo, sem que se possa saber qual dessas proposições deverá ser aplicada ao caso singular", dando origem, no entender de Klug, à chamada antinomia real, "isto porque, em sendo contraditórias, as normas se excluem reciprocamente, obrigando o magistrado a solucionar o caso segundo os critérios de preenchimento de lacunas".

m) Zygmunt Ziembinski, por sua vez, alude à lacuna lógica ("aquela que ocorre em caso de antinomia"), lacuna axiológica ("na hipótese de lacuna de lege ferenda") e lacuna de construção, que seria a "verdadeira lacuna, surgindo quando houver uma omissão nas normas de organização de um sistema legal", configurando, assim, na ótica do citado autor, uma autêntica lacuna (DINIZ, 2002, p. 94).

n) Krings, de sua parte, traz à baila mais uma classificação sobre o tema, a saber: lacuna externa (que se situa fora do sistema legal, requerendo, para efeito do respectivo preenchimento, a extensão do sistema ao caso concreto não previsto, recorrendo-se, por exemplo, ao emprego da analogia) e lacuna interna (aquela que se apresenta dentro dos limites do sistema legal, requerendo a devida colmatação, e que "surge quando a lei emprega alguns termos, sem, contudo, fornecer sua definição, ou seja, quando tal lei é ambígua, obscura ou imprecisa") (DINIZ, 2002, p. 95).

o) Diniz (2002, p. 95) menciona, ademais, a seguinte classificação assinalada por Betti:

...lacunas ínsitas ab origene na norma ou supervenientes com o decurso do tempo ao modificarem-se as relações; lacunas resultantes da falta de valorações normativas, daquelas de que se deduz a máxima de decisão (lacunas de valoração) ou de sua inadequação no tratamento jurídico; lacunas dependentes de definições totais ou parciais de quaisquer elementos do tipo legal ou do estatuído no preceito (lacuna de previsão); lacunas dependentes da alternatividade, isto é, decorrentes de mudanças de relações fáticas; lacunas de colisão, que supõe a exigência de uma adequação e de um ponto de acordo das normas existentes com a sobrevida (DINIZ, 2002, p. 95). 
p) Por fim, Diniz (2002, p. 95), ante o dinamismo inerente ao Direito, propõe a seguinte classificação: lacuna normativa ("quando se tiver ausência de norma sobre determinado caso"), lacuna ontológica ("se houver norma, mas ela não corresponder aos fatos sociais, quando, por exemplo, o grande desenvolvimento das relações sociais, o progresso técnico acarretarem o ancilosamento da norma positiva") e lacuna axiológica ("no caso de ausência de norma justa, ou seja, quando existe um preceito normativo, mas, se for aplicado, sua solução será insatisfatória ou injusta").

\section{INTEGRAÇÃO DO DIREITO}

Ao abordar o tema em epígrafe, Ferraz Jr. (2015, p. 262-263) assevera que a "constatação de um possível descompasso entre o Direito Positivo e as necessidades sociais trouxe à tona a questão da lacuna" e, por conseguinte, a reflexão a respeito dos modos por meio dos quais se procede à integração do Direito.

A doutrina, de um modo geral, reconhece que o Direito brasileiro contempla dois mecanismos por meio dos quais, sob o prisma dinâmico, completa-se o ordenamento jurídico: a autointegração e a heterointegração.

Autointegração "consiste na integração cumprida através do mesmo ordenamento, no âmbito da mesma fonte dominante, sem recorrência a outros ordenamentos e com o mínimo recurso a fontes diversas da dominante" (BOBBIO, 1999, p. 147), sendo a analogia o procedimento típico (DINIZ, 2002, p. 139).

Por sua vez, heterointegração, consoante as lições de Bobbio (1999, p. 146-147), e de acordo com a terminologia adotada por Carnelluti, traduz a integração realizada por intermédio do recurso a ordenamentos distintos, bem como, a fontes diversas daquela que é dominante. Era o caso, historicamente notado por Bobbio (1999, p. 147), em que o juiz, deparando-se com uma lacuna no Direito Positivo, recorria ao Direito Natural - concebido, durante o predomínio das correntes jusnaturalistas, como um sistema perfeito -, posto que uma das fun- 
ções deste era exatamente preencher os vazios daquele (caracterizado, ao contrário, por ser um sistema imperfeito). Conforme lembrado por Bobbio, o artigo $7^{\circ}$. do Código Civil Austríaco (1812) previa que "nos casos dúbios, que não podem ser resolvidos com normas de Direito Positivo, o juiz deve recorrer aos princípios do Direito Natural (natürliche Rechtsgrundsätze)".

Segundo a doutrina contemporânea, o costume jurídico e a equidade são exemplos de recursos a serem empregados quando do manejo da técnica da heterointegração, havendo dissensão quanto aos princípios gerais de Direito, os quais, de acordo com o entendimento de Diniz (2002, p. 139) "podem ser tidos como auto-integração (analogia juris) e como heterointegração (recurso aos princípios de Direito Comparado)", embora a autora os considere "como instrumentos heterointegrativos".

\section{Meios SUPLetivos das lacunas}

Meios supletivos das lacunas são os procedimentos por meio dos quais o intérprete preenche a lacuna detectada. Pressupõe, portanto, que o operador haja lançado mão de todas as regras de interpretação postas à sua disposição e, ainda assim, não tenha conseguido identificar alguma norma jurídica particularmente aplicável ao caso concreto. Tais instrumentos estão arrolados no artigo $4^{\circ}$. da Lei de Introdução às Normas do Direito Brasileiro (Decreto-Lei $\mathrm{n}^{\circ}$. 4.657/42): analogia, costumes e princípios gerais de Direito.

A analogia, enquanto autêntico procedimento de autointegração, consiste na aplicação de uma norma jurídica destinada a reger determinado caso a uma hipótese não disciplinada pelo Direito, havendo semelhança entre ambas as situações. Ferraz Jr. (2015, p. 265) ensina que "o uso da analogia, no Direito, funda-se no princípio geral de que se deve dar tratamento igual a casos semelhantes", razão pela qual "a semelhança deve ser demonstrada sob o ponto de vista dos efeitos jurídicos, supondo-se que as coincidências sejam maiores e juridicamente mais significativas que as diferenças". Assim, segundo o referido autor, "demonstrada a semelhança entre dois casos, o intérprete percebe, 
simultaneamente, que um não está regulado e aplica a ele a norma do outro". A figura jurídica em questão, conforme assinalado por Diniz (2002, p. 142), já era adotada supletivamente no âmbito do Direito Romano, estando presente numa frase atribuída a Aulus Gellius: analogia est similium declinatio, quam quidam latine proportionem vocant. Assim, esquematicamente, o emprego da analogia pode ser retratado da seguinte forma:

Caso $\mathbf{X} \rightarrow$ regido pela norma jurídica $\mathbf{Y}$. Logo, não há lacuna

Caso $\mathbf{Z} \rightarrow$ não disciplinado pelo Direito. Consequentemente, há lacuna

Caso Z é semelhante ao Caso $\mathbf{X}$

Solução $\rightarrow$ aplica-se (analogicamente) a norma jurídica $\mathbf{Y}$ ao $\mathbf{C a s o} \mathbf{Z}$

Com efeito, a aplicação da analogia requer a observância de alguns requisitos. É preciso, em primeiro lugar, verificar se o caso apresentado não foi disciplinado pelo Direito, ou seja, se há efetivamente uma lacuna. Além desse requisito, a aplicação de uma regra jurídica existente no ordenamento a um caso não regulamentado exige a constatação de semelhança entre as duas hipóteses (a regulada e a não disciplinada pela normatividade jurídica). Assim, de acordo com o esquema citado, deve existir semelhança entre os casos $\mathbf{X}$ e $\mathbf{Z}$.

A doutrina é unânime em afirmar que o emprego da analogia demanda, ademais, que a mesma razão que levou o intérprete a decidir o caso $\mathbf{X}$, aplicando, para tanto, a regra $\mathbf{Y}$, esteja igualmente presente na decisão a ser tomada quanto à hipótese lacunosa $(\mathbf{Z})$, que também deverá sofrer a incidência da norma $\mathbf{Y}$ (vide o esquema citado). Trata-se, como se vê, de um raciocínio que se ampara na identidade de razão, exatamente o que fundamenta a incidência da norma $\mathbf{Y}$ ao caso não disciplinado (Z), mas que é substancialmente semelhante à situação $\mathbf{X}$, devendo, pois, receber a mesma regência normativa. Nos exatos termos de tal requisito, cite-se a lição de Montoro: 
Não basta, porém, a semelhança de casos ou situações. É necessário que exista a mesma razão para que o caso seja decidido de igual modo. Ou, como diziam os romanos, onde existe a mesma razão da lei, cabe também a mesma disposição (ubi eadem legis ratio, ibi eadem legis dispositio) (MONTORO, 2011, p. 433).

Quanto à natureza jurídica da analogia, a doutrina aponta as seguintes concepções:

a) Alguns autores a concebem como um autêntico método interpretativo.

b) Para outros, trata-se de um dos meios por intermédio dos quais o Direito se revela, se exterioriza, sendo, portanto, uma autêntica fonte do Direito.

Advirta-se que a analogia não constitui propriamente uma técnica de interpretação, como a princípio possa parecer, mas verdadeira fonte do Direito, ainda que subsidiária e assim reconhecida pelo legislador no artigo $4^{\circ}$ da Lei de Introdução ao Código Civil [atual Lei de Introdução às Normas do Direito Brasileiro] (VENOSA, 2006, p. 140).

c) Ainda no que concerne à mesma divergência, a analogia, segundo um segmento doutrinário e jurisprudencial, constitui-se em um meio de integração normativa, tendo em vista sua inserção no artigo $4^{\circ}$. da Lei de Introdução às Normas do Direito Brasileiro (Decreto-Lei n ${ }^{\circ}$. 4.657/42).

Quanto à analogia, ela está indicada como modelo a ser utilizado pelo intérprete no preenchimento da lacuna, com base em outra norma jurídica que não foi feita para o caso examinado.

Assim, esse meio de integração consiste na aplicação da norma feita para um caso em outro semelhante, que não tem a previsão nomeada no sistema (NUNES, 2002, p. 263). 
I - Aplicação analógica do disposto no art. 150, III, c, da $\mathrm{CF}$, para assegurar ao contribuinte do ICMS o direito à observância do princípio da noventena em relação a decretos estaduais que implementaram o sistema de recolhimento do tributo por substituição tributária, mas não previram prazo razoável de adaptação em favor das substituídas, e afastar a consequente violação aos princípios da razoabilidade, da não surpresa e da segurança jurídica.

II - Adoção de um dos métodos de integração da norma previstos no art. $4^{\circ}$ da Lei de Introdução ao Código Civil. Controvérsia que se restringe ao 'terreno puramente infraconstitucional', consoante entendimento assentando pelo Plenário da Corte no RE 202.626/DF, Rel. Min. ILMAR GALVÃO.

III - Suposta violação aos princípios da razoabilidade e da segurança jurídica. Matéria não impugnada no recurso extraordinário. Fundamento autônomo e suficiente à manutenção do julgado. Incidência da Súmula 283/ STF. Precedente: RE 677.142/MG, Rel. Min. TEORI ZAVASCKI.

IV - Agravo regimental a que se nega provimento.

(STF, Segunda Turma, Agravo Regimental no Recurso Extraordinário com Agravo no 713.196/RS, Rel. Min. RICARDO LEWANDOWSKI, julgamento em 10.06.2014).

Compartilhando a mesma linha de raciocínio que concebe a figura em tela como meio de integração, entende Diniz (2002, p. 153) que a analogia não é uma "técnica interpretativa nem tampouco uma fonte do Direito, mas um procedimento que serve para integrar normas".

O segundo método de suprimento de lacunas previsto no artigo $4^{\mathrm{o}}$. da Lei de Introdução às Normas do Direito Brasileiro (Decreto-Lei $\mathrm{n}^{\mathrm{o}} .4 .657 / 42$ ) é o costume jurídico, cabendo destacar, desde logo, que tal figura não se confunde com as denominadas regras de trato social (regras de boa educação, de cortesia, de higiene, usos sociais etc.), residindo a distinção fundamental justamente na força obrigatória e na necessidade jurídica, elementos encontrados apenas no costume. 
O Direito brasileiro, por razões históricas, é predominantemente escrito, figurando a lei (em sentido amplo), como a principal fonte do sistema normativo pátrio. Não obstante tal realidade, a presente constatação não afasta a possibilidade de haver normas jurídicas não-escritas (normas costumeiras ou consuetudinárias), cujo processo de criação, de forma diferente das normas escritas, não se opera de modo institucionalizado, mas, ao revés, pela interferência da própria sociedade. Assim, o costume jurídico, uma das mais antigas fontes do Direito, tendo precedido à própria lei escrita, atua contemporaneamente como uma autêntica fonte subsidiária (secundária, mediata ou indireta) do Direito Brasileiro, conforme amplamente reconhecido pela doutrina.

Deveras, a lei, por mais extensa que seja em suas realizações, por mais que se desdobre em artigos, parágrafos e incisos, jamais poderá conter toda a infinidade de relações emergentes da vida social, que necessitam de uma garantia jurídica, devido à grande exuberância da realidade, tão variável de lugar para lugar, de povo para povo. Por isso, ante a insuficiência legal, é mister manter a seu lado, quando for omissa e quando não for possível sua extensão analógica, as fontes subsidiárias do Direito, que revelem o jurídico (DINIZ, 2002, p. 185).

Destarte, no plano conceitual, costume é a norma jurídica não-escrita, criada pela sociedade, sendo oriunda da prática constante, reiterada e uniforme de determinado comportamento, tudo aliado à convicção social acerca de sua necessidade jurídica. De modo diferente da lei escrita, cuja elaboração é certa, predeterminada e decorrente da atividade do Poder Público, que a elabora segundo os procedimentos previstos na Constituição Federal (mormente no que se refere ao denominado processo legislativo, arts. 59 a 69) e na legislação infraconstitucional (a Lei Complementar $n^{\circ} .95 / 98$ ), a origem do costume jurídico, consoante leciona o insigne Reale, não tem origem certa, nem se localiza ou é suscetível de localizar-se de maneira predeterminada. 
O Direito costumeiro [...] não tem origem certa, nem se localiza ou é suscetível de localizar-se de maneira predeterminada. Geralmente não sabemos onde e como surge determinado uso ou hábito social, que, aos poucos, se converte em hábito jurídico, em uso jurídico.

O Direito costumeiro nasce por toda parte, de maneira anônima, ao passo que a lei, desde a sua origem, se reveste de segurança de certeza (REALE, 2002, p. 156).

No que se refere ao aspecto estrutural da norma costumeira, assevera Ferraz Jr. (2015, p. 199) que o costume, como fonte das normas consuetudinárias, possui em sua composição um elemento substancial (o uso reiterado no tempo) e um elemento relacional ("o processo de institucionalização que explica a formação da convicção da obrigatoriedade e que se explicita em procedimento, rituais ou silêncios presumidamente aprovadores"), dos quais decorrem a validade e a eficácia do costume.

Com efeito, segundo pacífica doutrina, pode-se afirmar que o costume jurídico possui dois elementos constitutivos: o elemento externo (material ou relacional) e o elemento interno (espiritual ou substancial). O primeiro nasce com a constância da repetição, por parte da sociedade, dos mesmos atos, cuja formação é lenta, longa e sedimentária; o segundo elemento, por sua vez, consiste na convicção, por parte dos membros da comunidade, de que a norma consuetudinária é juridicamente necessária. Nesse sentido, adverte Bitencourt (2011, p. 162) que a ausência de tal convicção reduz o costume a um "simples uso social, sem o caráter de exigibilidade".

Nos termos do artigo $4^{\circ}$. da Lei de Introdução às Normas do Direito Brasileiro (Decreto-Lei $n^{\circ}$. 4.657/42), o costume, não obstante sua inegável qualidade enquanto meio de suprimento (heterointegração) das lacunas da lei, figura, ademais, como fonte subsidiária do Direito pátrio. Nesse particular, explica Ferraz Jr. (2015, p. 267) que "a imposição do costume como meio integração da lei no art. $4^{\circ}$ da Lei de Introdução cria uma subordinação daquele a esta", motivo pelo qual, a princípio, o costume será praeter legem, prevalecendo, pois, a lei. 
Afirma-se, pois, que o costume jurídico, além de atuar como um dos meios de suprimento de lacunas, figura também como fonte subsidiária do Direito Brasileiro (DINIZ, 2002, p. 186).

De igual modo, nos termos do artigo $4^{\circ}$. da Lei de Introdução às Normas do Direito Brasileiro, os denominados princípios gerais de Direito figuram como método de autointegração. Princípios, para Reale (2002, p. 305), “'São verdades fundantes' de um sistema de conhecimento, como tais admitidas, por serem evidentes ou por terem sido comprovadas, mas também por motivo de ordem prática de caráter operacional, isto é, como pressupostos exigidos pelas necessidades da pesquisa e da práxis".

Segundo explica Mello (2012, p. 54), princípio, por definição, constitui-se em um "mandamento nuclear de um sistema, verdadeiro alicerce dele, disposição fundamental que se irradia sobre diferentes normas, compondo-lhes o espírito e servindo de critério para exata compreensão e inteligência delas, exatamente porque define a lógica e a racionalidade do sistema normativo, conferindo-lhe a tônica que lhe dá sentido harmônico".

Os princípios gerais de Direito podem ser encontrados de forma expressa ou implícita (tácita). Os primeiros, como a própria expressão sugere, são aqueles que se encontram expressamente previstos no Ordenamento Jurídico. Os princípios implícitos, por sua vez, são aqueles que, embora não previstos expressamente no ordenamento jurídico, podem ser perfeitamente extraídos a partir do sistema normativo, sendo, portanto, admitidos pela doutrina e jurisprudência. A título de exemplo, cite-se o princípio da insignificância (ou da bagatela), o qual, embora não previsto na legislação penal brasileira, tem sido com frequência aplicado pelo Poder Judiciário brasileiro, inclusive pelo Supremo Tribunal Federal, cuja incidência concreta tem o condão de afastar a própria tipicidade penal da conduta, não havendo, portanto, crime, exatamente por faltar um de seus elementos essenciais (a tipicidade penal). 


\section{Considereções FINAIS}

Em sua obra Teoria do Ordenamento Jurídico, Bobbio (1999, p. 19) menciona uma frase cuja essência sintetiza boa parte do conteúdo desenvolvido neste texto: "as normas jurídicas nunca existem isoladas, mas sempre em um contexto de normas com relações particulares entre si". A presente citação evidencia, em primeiro lugar, que "as regras jurídicas constituem sempre uma totalidade", isto é, formam um ordenamento jurídico. Da mesma forma, a referida elocução põe em relevo a importância não apenas do estudo da norma jurídica individualmente considerada, mas, também, de sua inter-relação com outras normas integrantes de um dado sistema.

Bobbio, na mesma obra, discorre sobre os atributos da unidade, coerência e completude. Por completude, segundo a lição de Bobbio, "entende-se a propriedade pela qual um ordenamento jurídico tem uma norma para regular qualquer caso". Diante de tal definição, e considerando que a ausência de uma norma é tradicionalmente denominada de lacuna, reveladora de uma imperfeição do sistema, o termo completude, por conseguinte, traduz exatamente a falta de lacuna, problema que, nos termos da atual Lei de Introdução às Normas do Direito Brasileiro, há de ser solucionado pelos mecanismos supletivos: analogia, costume e princípios gerais do Direito.

\section{REFERÊNCIAS}

BITENCOURT, Cezar. Tratado de Direito Penal, Parte Geral, v. 1, 16. ed. São Paulo: Saraiva, 2011.

BOBBIO, Norberto. Teoria do Ordenamento Jurídico, 10. ed. Brasília: Editora Universidade de Brasília, 1999.

BRASIL. STF, Segunda Turma, Agravo Regimental no Recurso Extraordinário com Agravo no ${ }^{\mathbf{7}}$ 713.196/RS, Rel. Min. Ricardo Lewandowski, julgamento em 10.06.2014. 
DINIZ, Maria Helena. Compêndio de Introdução à Ciência do Direito, 12. ed. São Paulo: Saraiva, 2000.

. As Lacunas no Direito, 7. ed. São Paulo: Saraiva, 2002.

. Lei de Introdução ao Código Civil Brasileiro Interpretada, 8. ed. São Paulo: Saraiva, 2001.

FERRAZ JR., Tercio Sampaio. Introdução ao Estudo do Direito, Técnica, Decisão, Dominação, 8. ed. São Paulo: Atlas, 2015.

GUSMÃO, Paulo Dourado de. Introdução ao Estudo do Direito, 27. ed. Rio de Janeiro: Forense, 2000.

KELSEN, Hans. Teoria Pura do Direito, 2. ed. São Paulo: Martins Fontes, 1987.

LAFER, Celso. A Reconstrução dos Direitos Humanos: um Diálogo com o Pensamento de HANNAH ARENDT. São Paulo: Companhia das letras, 1988.

MELLO, Celso Antonio Bandeira de. Curso de Direito Administrativo, 29. ed. São Paulo: Malheiros Editores, 2012.

MONTORO, André Franco. Introdução à Ciência do Direito, 29. ed. São Paulo: Revista dos Tribunais, 2011.

NUNES, Rizzatto. Manual de Introdução ao Estudo do Direito, 4. ed. São Paulo: Saraiva, 2002.

REALE, Miguel. Lições Preliminares de Direito, 26. ed. São Paulo: Saraiva, 2002.

SILVA, José Afonso Da. Curso de Direito Constitucional Positivo, 38. ed. São Paulo: Malheiros, 2015.

SOARES, Ricardo M. F. Elementos de Teoria Geral do Direito. São Paulo: Saraiva, 2013.

STRECK, Lenio. Hermenêutica Jurídica e(m) Crise: uma Exploração Hermenêutica da Construção do Direito, 7. ed. Porto Alegre: Livraria do Advogado, 2007.

VENOSA, Sílvio. Introdução ao Estudo do Direito - Primeiras Linhas, 2. ed. São Paulo: Atlas, 2006. 


\section{SOBRE O AUTOR}

\section{ReIS Friede}

Desembargador Federal e Vice-Presidente do TRF/2 ${ }^{\mathrm{a}}$. Região. Ex-membro do Ministério Público e Professor Titular da Universidade Veiga de Almeida e do Mestrado em Desenvolvimento Local do Centro Universitário Augusto Motta (UNISUAM).

CV: http://lattes.cnpq.br/6180019303336522

E-mail: reisfriede@hotmail.com

Submetido em: 8-11-2017

Aceito em:4-4-2018 